\title{
THE LATTICE OF THE 1.0 GeV VSX STORAGE RING
}

\author{
H. Takaki, ${ }^{\prime}$ K. Harada, T. Koseki, N. Nakamura, Y. Kamiya, ISSP, U. of Tokyo \\ Y. Kobayashi, KEK-PF
}

\section{Abstract}

The University of Tokyo has been promoting a future project to construct a third-generation VUV and Soft Xray light source (VSX). The VSX ring has an energy of $1.0 \mathrm{GeV}$, an emittance of about $0.7 \mathrm{~nm} \bullet \mathrm{rad}$, a circumference of about $230 \mathrm{~m}$ and two $30 \mathrm{~m}$ long straight sections for insertion devices. The most significant characteristic of the VSX ring is that its emittance is below a diffraction limit for the photon energy of $100 \mathrm{eV}$. It can provide the VUV and Soft X-ray light with a maximum brilliance above $10^{20}$ [photons $/ \mathrm{sec} / \mathrm{mm}^{2} / \mathrm{mrad}^{2} / 0.1 \%$ b.w.] using a long undulator installed in $30 \mathrm{~m}$ long straight section.

\section{INTRODUCTION}

The University of Tokyo aims at constructing a thirdgeneration VUV and Soft X-ray light source (VSX) in the new Kashiwa Campus. In general, a "third-generation" light source is characterized by a low emittance and a long straight section for insertion devices.

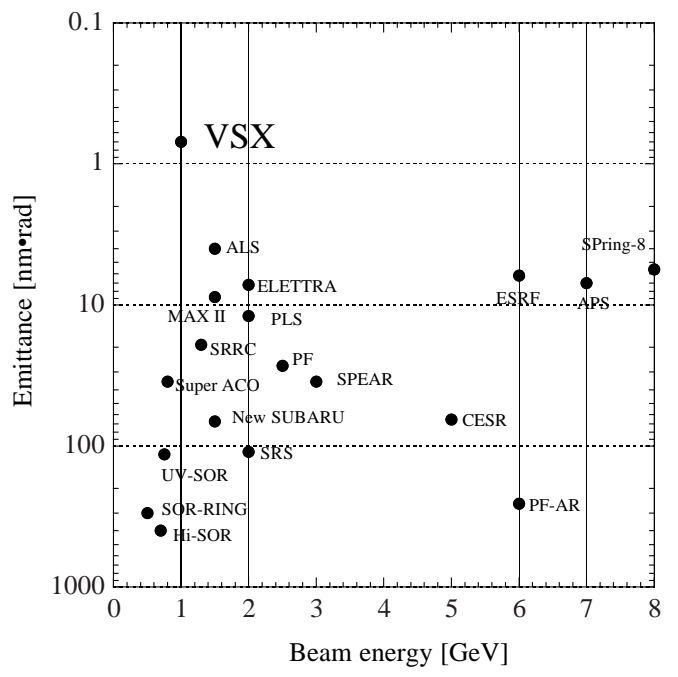

Figure 1: The emittance versus the beam energy for the typical synchrotron light sources in the world.

"Email: takaki@issp.u-tokyo.ac.jp

The beam emittance of the VSX ring is able to reach the diffraction limit, $\varepsilon \sim \lambda / 4$ where $\lambda$ is the wavelength of the emitted photon. For the typical photon energy of 100
$\mathrm{eV}(\lambda \sim 12 \mathrm{~nm})$, the diffraction limit is about $1 \mathrm{~nm} \bullet \mathrm{rad}$. The minimum value of the beam emittance is 0.73 nm•rad, which is extremely small compared with the existing synchrotron light sources around the world (see Fig. 1). For a maximum current of $200 \mathrm{~mA}$, the emittance becomes slightly larger than $1 \mathrm{~nm} \bullet$ rad due to the intrabeam scattering.

The VSX ring has two $30 \mathrm{~m}$ long straight sections for insertion devices. The $27 \mathrm{~m}$ long undulator will be installed in one of them, which is capable of providing a unprecedentedly brilliant synchrotron light in the VUV region.

In the following sections, the lattice configuration, the linear optics, the chromaticity correction and the dynamic aperture are reported.

\section{LATTICE}

The storage ring has a shape of racetrack with a circumference of $230.2 \mathrm{~m}$ (see Fig. 2). It is composed of 22 Normal Cells, four Matching Sections including four Half Cells and two $30 \mathrm{~m}$ long straight sections. The Half Cell is slightly different from a half of Normal Cell.

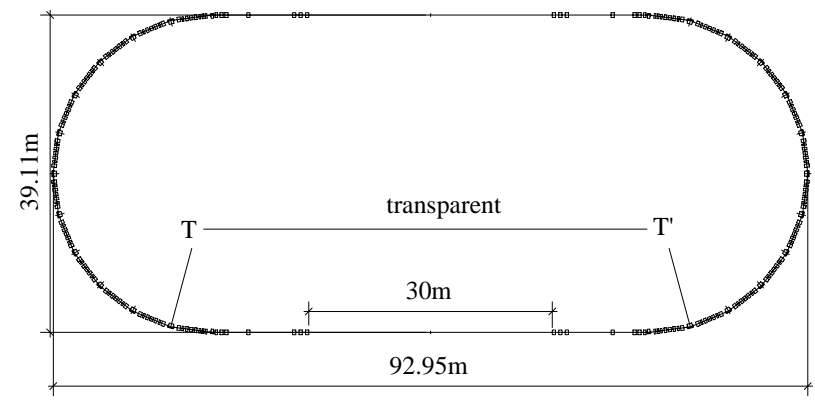

Figure 2: The VSX ring layout

\subsection{Normal Cell}

The lattice configuration of the Normal Cell is of Theoretical Minimum Emittance type [1], which has an emittance smaller than the DBA type by a factor of three. The theoretical minimum emittance is given by,

$$
\varepsilon_{x 0}^{\min }=\frac{1}{12 \sqrt{15} J_{x}} C_{q} \gamma^{2}\left(\frac{2 \pi}{N}\right)^{3},
$$

where $C_{q}=(55 / 32 \sqrt{3})(\mathrm{h} m c), \quad J_{x}$ is the damping partition number and $\mathrm{N}$ is the number of bending magnets. As $J_{x}$ is almost equal to 1 for the bending magnets of the separated function type, the theoretical minimum emittance is $0.56 \mathrm{~nm} \bullet \mathrm{rad}$ for $\mathrm{N}=24$.

To realize this emittance in the VSX ring, the horizontal betatron function $\beta_{\mathrm{x}}$ and dispersion function $\eta_{\mathrm{x}}$ 
should be $0.075 \mathrm{~m}$ and $0.0063 \mathrm{~m}$ at the center of a bending magnet. Thus a very small beam size less than 10 $\mu \mathrm{m}$ is attained at the magnet center, so that a high brilliant light can be supplied to bending beamlines.

\subsection{Matching Section}

A $T$ - $T^{\prime}$ Section (see Fig.2 and 3) is composed of a long straight section and two Matching Sections. The Half Cell, the section between SD and BH, reduces the $\eta_{\mathrm{x}}$ of Normal Cells to be zero. For the $T-T^{\prime}$ Section to be "transparent" for the non-linear effects and behave as a Normal Cell, the phase advances should be,

$$
\begin{aligned}
& \Delta \phi_{\mathrm{x}}=2 \pi \mathrm{m}+\phi_{\mathrm{x} \text { Normal Cell, }} \\
& \Delta \phi_{\mathrm{y}}=2 \pi \mathrm{n}+\phi_{\mathrm{y} \text { Normal Cell. }}
\end{aligned}
$$

For the VSX ring, $m=1$ and $n=2$ are chosen. Then the optics looks as if it were perfectly 24 -fold symmetric for on-momentum particles.

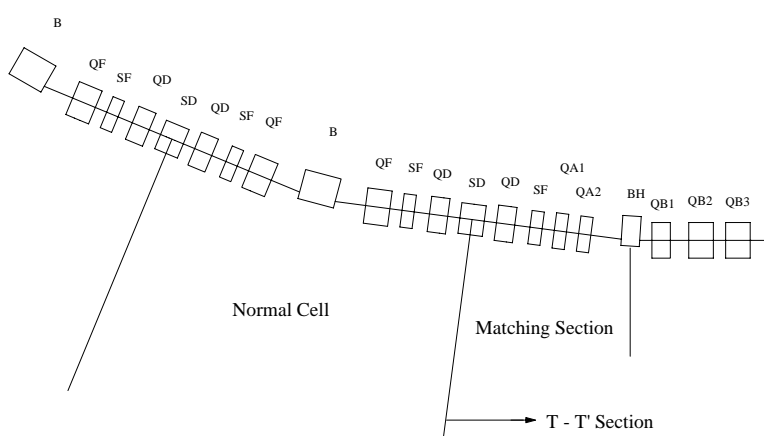

Figure 3: The Matching Section layout

\section{OPERATION MODE}

Since the Touschek effect is severe for Low Emittance Mode (LEM), a moderate operation of High Emittance Mode (HEM) is prepared for easy commissioning and stable operation.

\subsection{Low Emittance Mode}

The emittance of Low Emittance Mode is $0.73 \mathrm{~nm} \bullet \mathrm{rad}$. The fundamental parameters of this mode are listed in Table 1. The Touschek lifetime is 5 hours due to the small beam size, while the Coulomb lifetime is about 10 hours at $10^{-10}$ Torr.

Table 1: Fundamental parameters of the VSX ring

\begin{tabular}{|c|c|c|}
\hline Energy & $\mathrm{E}[\mathrm{GeV}]$ & 1.0 \\
\hline Lattice Type & & $\begin{array}{l}\text { Theoretical } \\
\text { Minimum } \\
\text { Emittance }\end{array}$ \\
\hline Superperiod & Ns & $\sim 24$ \\
\hline Circumference & $\mathrm{C}[\mathrm{m}]$ & 230.2 \\
\hline Long Straight Section & & $30 \mathrm{~m} \times 2$ \\
\hline Natural Emittance & $\varepsilon_{\mathrm{X} 0}[\mathrm{~nm} \bullet \mathrm{rad}]$ & 0.732 \\
\hline Energy Spread & $\sigma_{\mathrm{E}} / \mathrm{E}$ & $5.67 \times 10^{-4}$ \\
\hline Momentum Compaction Factor & $\alpha$ & $4.49 \times 10^{-4}$ \\
\hline Horizontal & $v_{X}$ & 17.4 \\
\hline
\end{tabular}
(Low Emittance Mode)

\begin{tabular}{llcc} 
& Vertical & $v_{\mathrm{y}}$ & 7.71 \\
Natural Chromaticity Horizontal & $\xi_{\mathrm{x}}$ & -38.7 \\
& Vertical & $\xi_{\mathrm{y}}$ & -39.3 \\
\multirow{4}{*}{ Damping Time } & Horizontal & $\tau_{\mathrm{x}}[\mathrm{msec}]$ & 39.6 \\
& Vertical & $\tau_{\mathrm{y}}[\mathrm{msec}]$ & 39.8 \\
& Longitudinal & $\tau_{\mathrm{z}}[\mathrm{msec}]$ & 19.9 \\
\multirow{2}{*}{ Revolution Frequency } & $\mathrm{f}_{\mathrm{rev}}[\mathrm{MHz}]$ & 1.302 \\
RF Voltage & $\mathrm{V}_{\mathrm{RF}}[\mathrm{MV}]$ & 0.5 \\
RF Frequency & $\mathrm{f}_{\mathrm{RF}}[\mathrm{MHz}]$ & 500.1 \\
Synchrotron Tune & $\mathrm{v}_{\mathrm{S}}$ & 0.0037 \\
Bunch Length & $\sigma_{\mathrm{z}}[\mathrm{mm}]$ & 2.52 \\
RF-bucket Height & $(\Delta \mathrm{E} / \mathrm{E})_{\mathrm{RF}}$ & 0.040 \\
\hline
\end{tabular}

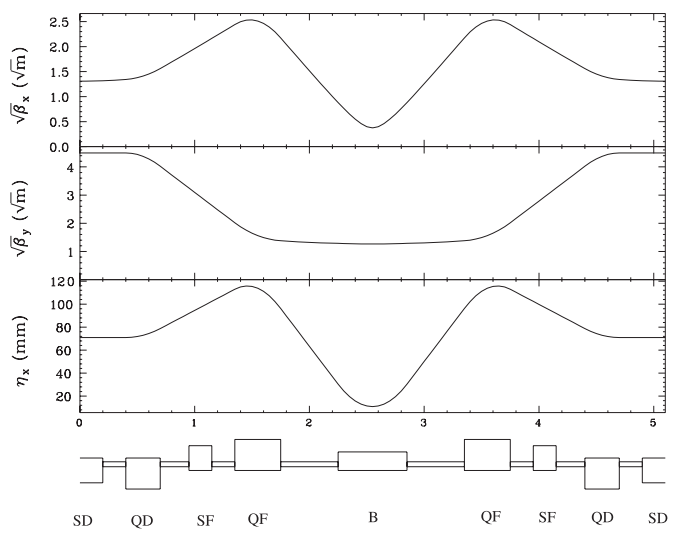

Figure 4: The optics of the Normal Cell (LEM)

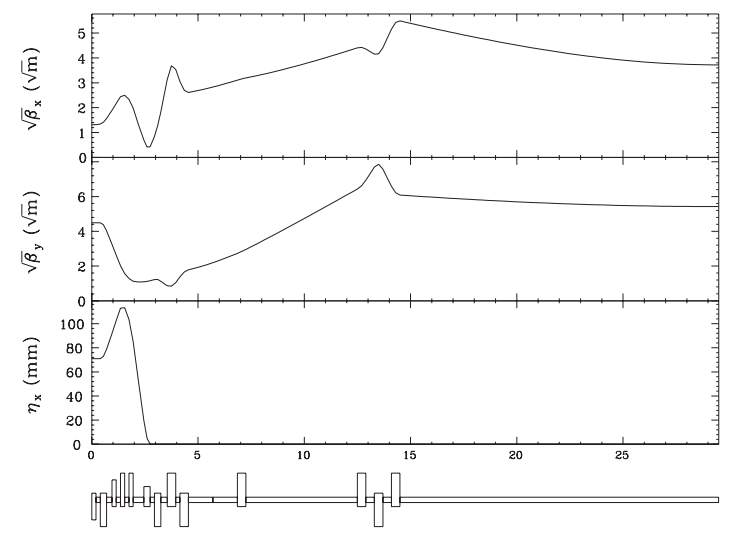

Figure 5: The optics of the Matching Section (LEM)

The optics of the Normal Cell and the Matching Section are shown in Fig. 4 and 5. The parameters of magnets are listed in Table 2.

The chromaticity is corrected by only 2 families of sextupoles (SF, SD) in the Normal Cells, but the so-called harmonic sextupole is not used. The horizontal and vertical dynamic apertures after chromaticity correction are shown in Fig. 8.

\subsection{High Emittance Mode}

The emittance of High Emittance Mode is $2.6 \mathrm{~nm} \bullet$ rad. The fundamental parameters of this mode are listed in Table 3. Touschek lifetime becomes over 10 hours. 
The optics of the Normal Cell and the Matching Section are shown in Fig. 6 and 7. The horizontal and vertical dynamic apertures after chromaticity correction are shown in Fig. 8.

Table 2: Parameters of Magnets

\begin{tabular}{|c|c|c|c|}
\hline & & LEM & HEM \\
\hline B & {$[\mathrm{T}]$} & $1.450[\mathrm{~T}]$ & $1.450[\mathrm{~T}]$ \\
\hline QF & $\mathrm{B}^{\prime} 1 / \mathrm{B} \rho[1 / \mathrm{m}]$ & 1.664 & -0.622 \\
\hline QD & $\mathrm{B}^{\prime} 1 / \mathrm{B} \rho[1 / \mathrm{m}]$ & -0.715 & 0.630 \\
\hline SF & $\left(\mathrm{B}^{\prime \prime} 1 / \mathrm{B} \rho\right)\left[1 / \mathrm{m}^{2}\right]$ & 33.168 & -7.590 \\
\hline SD & $\left(\mathrm{B}^{\prime \prime} 1 / \mathrm{B} \rho\right)\left[1 / \mathrm{m}^{2}\right]$ & -26.747 & 4.015 \\
\hline
\end{tabular}

Table 3: Parameters for High Emittance Mode

\begin{tabular}{lcc}
\hline Natural Emittance & $\varepsilon_{\mathrm{x} 0}[\mathrm{~nm} \bullet \mathrm{rad}]$ & 2.64 \\
Momentum Compaction Factor & $\alpha$ & $1.02 \times 10^{-3}$ \\
Natural Chromaticity Horizontal & $\xi_{\mathrm{x}}$ & -34.6 \\
& $\xi_{\mathrm{y}}$ & -18.7 \\
Vertical & $\mathrm{V}_{\mathrm{RF}}[\mathrm{MV}]$ & 0.7 \\
Bunch Loltage & $\sigma_{\mathrm{z}}[\mathrm{mm}]$ & 3.20 \\
RF-bucket Height & $(\Delta \mathrm{E} / \mathrm{E}) \mathrm{RF}$ & 0.032 \\
\hline
\end{tabular}

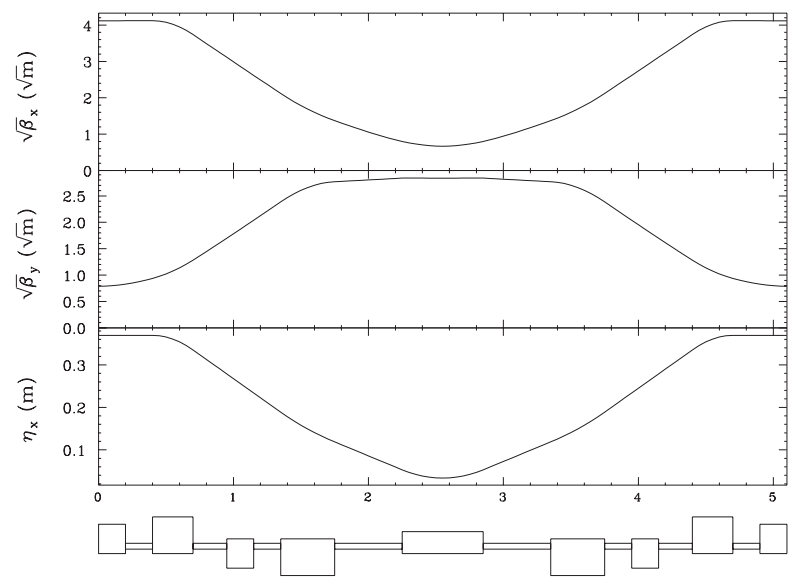

Figure 6: The optics of the Normal Cell (HEM)

Figure 7: The optics of the Matching Section (HEM)

Figure 8: The horizontal and vertical dynamic apertures normalized by $\sqrt{\beta \varepsilon \varepsilon_{x 0}}$.

\section{REFERENCES}

[1] Y. Kamiya and M. Kihara, "On the design guideline for the low emittance synchrotron radiation source", KEK 83-16.
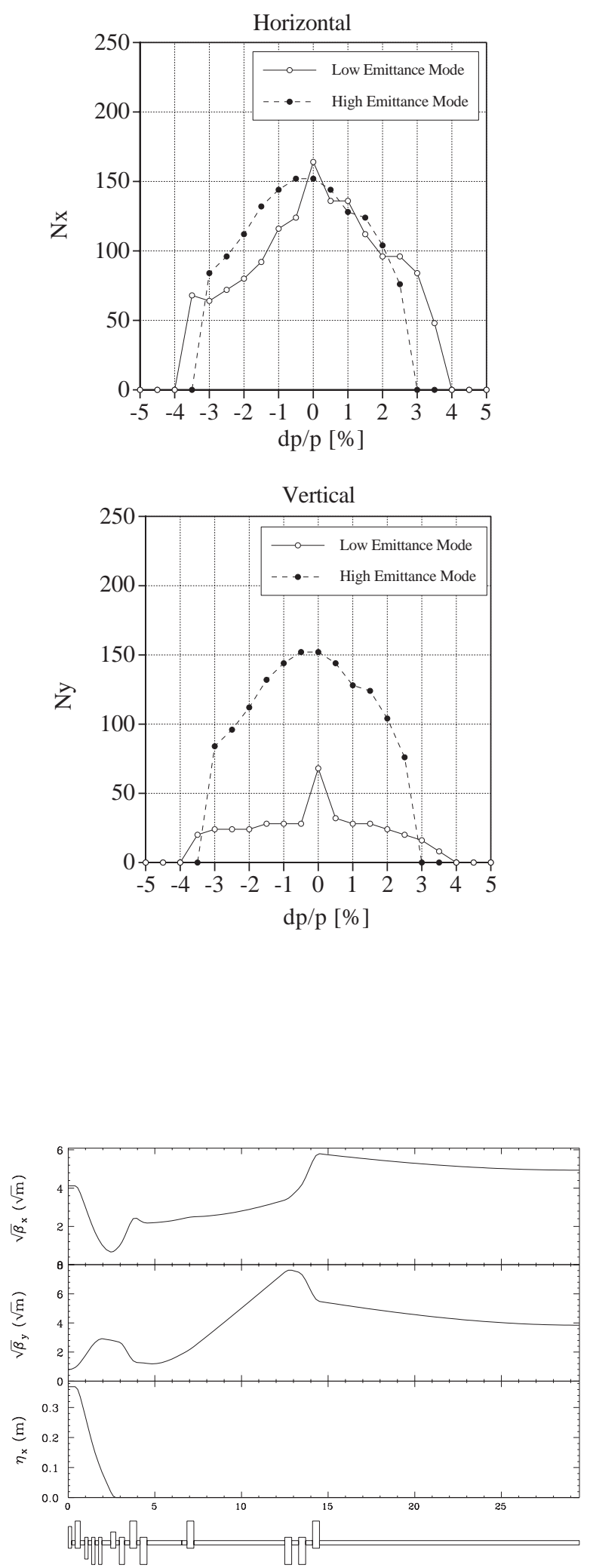